\title{
THE HABITS AND DISTRIBUTION OF \\ CRYPTOCERUS ROHWERI WHEELER (HYMENOPTERA： FORMICIDAE)
}

\author{
By \\ William S. Creighton, City College, New York ${ }^{1}$ \\ AND \\ William L. Nutting, University of Arizona ${ }^{2}$
}

When W. M. Wheeler described Cryptocerus rohweri in I9I6 he stated that the specimens which Rohwer sent him had been taken by Chrisman in a canyon of the Santa Catalina Mountains of Arizona and that they had been nesting in the dead limbs of a palo verde tree (I). There was no reason for Wheeler to question that the host tree was Cercidium torreyanum, but this question has since arisen and it is advisable to consider it here. The host plant identification appears to have been made from the dead limb sent in with the ants. Chrisman's field notes stated only that his specimens were nesting in "palo verde", which would cover either of the two species of Cercidium in the Santa Catalina area. But in this area C. torreyanum is scarce and it usually occurs at elevations below those where rohweri has been taken. The abundant and widespread species is $C$. microphyllum and all seven colonies of rohweri which we took in the Santa Catalinas were nesting in this tree. The probability is that

\begin{tabular}{|c|c|c|c|c|}
\hline $\begin{array}{r}\text { TABLE } 1 . \quad \text { Distr } \\
\text { STATION }\end{array}$ & $\begin{array}{l}\text { UtIONAa ID } \\
\text { ELEVATION }\end{array}$ & $\begin{array}{l}\text { for } \\
\text { NESTS }\end{array}$ & $\begin{array}{r}\text { Cryptocerus } \\
\text { NEST SITE }\end{array}$ & $\begin{array}{c}\text { rohwert Wheeler } \\
\text { COLLECTOR }\end{array}$ \\
\hline STA. CATALINA MTS. & & & & \\
\hline Buehman Canyon & - & 1 & palo verde & M. Chrisman \\
\hline Brush Corrals & $3700^{\prime}$ & 1 & palo verde & M. Chrisman \\
\hline Sabino Canyon & $3000^{\prime}$ & 2 & hackberry & E. D. Algert \\
\hline Sabino Canyon & - & 1 & not given & W. D. Edmonton \\
\hline Catalina Springs & - & 1 & not given & Hubbard \& Schwarz \\
\hline Catalina Foothills & $2800^{\prime}$ & 1 & palo verde & Wm. L. Nutting \\
\hline Catalina Foothills & $2800^{\prime}$ & 6 & palo verde & Wm. S. Creighton \\
\hline $\begin{array}{l}\text { Saguaro Nat. Mon. } \\
\text { BABOQUIVARI MTS. }\end{array}$ & $3100^{\prime}$ & strays & unknown & F. G. Werner \\
\hline Baboquivari Canyon & $3500^{\prime}$ & 1 & mesquite & Wm. S. Creighton \\
\hline Baboquivari Canyon & $3500^{\prime}$ & 1 & mesquite & C. H. Musgrove \\
\hline $\begin{array}{l}\text { AJo MOUntains } \\
\text { Alamo Canyon }\end{array}$ & & stray & unknown & E D B Bll \\
\hline ATASCOSA MTS. & - & stray & ИНКกО & C. D. Dan \\
\hline Peña Blanca Sprs. & $3700^{\prime}$ & 1 & live oak & Wm. S. Creighton \\
\hline
\end{tabular}

\footnotetext{
${ }^{1}$ Emeritus Professor, Department of Biology.

${ }^{2}$ Department of Entomology, College of Agriculture.

Manuscript received by the editor December 28, 1964.
} 
Chrisman's specimens came from $C$. microphyllum and not from C. torreyanum. The list in Table $\mathrm{I}$ is an expanded version of the list of localities for rohweri which M. R. Smith presented in his 1947 study of Cryptocerus (2).

While this list is unbalanced by the preponderance of records from the Santa Catalina Mountains it permits several conclusions. The range of rohweri covers a number of mountainous areas in southern Arizona. In each of these areas rohweri prefers to nest in canyon bottoms or on foothills at comparatively low elevations (2800-3700'). Although as yet unconfirmed, it is certain that the range of rohweri extends into northern Sonora. Peña Blanca Springs is (or perhaps better "was", for the area has been dammed and flooded) about five miles north of the border of Sonora and the mountains there run south into Mexico. It is clear that rohweri will accept at least four different trees as nest sites (Cercidium microphyllum, Prosopis juliflora, Quercus emoryi and Celtis sp.). Despite the large number of records from palo verde there are indications that rohweri has no special preference for this tree. In 1954 Creighton and Gregg showed that Crypt. texanus prefers to live in live oaks (3). This view was based not only on a preponderance of records for nests in live oak limbs but also on the fact that texanus nests in live oaks wherever these occur within its range. If rohweri prefers to nest in palo verde limbs it might be expected to do so over its entire range. As far as we have been able to determine it does not do so. In January of 1963 the senior author made an extensive survey of palo verde trees in the area between Benson and Ajo. This survey failed to produce a single nest of rohweri. Negative evidence of this sort is not conclusive but at least it may be said that the high incidence of rohweri nests in palo verde limbs in the Santa Catalina Mountains is not maintained in other parts of its range. It is possible that our present fragmentary view of the range of rohweri is an outcome of the fact that the tree which it prefers as a nest site has not yet been recognized.

Most of the observations in the remainder of this paper are based on three captive colonies of rohweri. One of these was observed by the junior author from October 1961 until August 1963. During this period the colony was studied at Tucson, less than five miles from its original nest site in the Santa Catalina Mountains. The senior author was less fortunate for the two captive colonies which he observed were carried far out of their range. From January to midApril of 1963 they were studied at Riverside, California. Thereafter until June 1964 they were studied at Rockport, Ontario. It would appear, however, that these expatriate colonies behaved in a normal 
fashion, for there was no noticeable difference between their behavior and that of the Tucson colony. This colony was housed in a plastic petri dish $90 \mathrm{~mm}$. in diameter. A short polyethylene tube connected this petri dish to a second one which served as a feeding chamber. This arrangement permitted a close watch on the development of the brood. The other two colonies were kept in sealed aquaria which contained oak block observation nests. This provided the ants with passages similar to those which they normally use and at the same time gave them the opportunity to forage outside the nest.

Most of the habits of rohweri are like those of texanus but there are some significant differences in the behavior of the two species. At maturity the rohweri colony is notably smaller than that of texanus. There are seldom more than seventy-five workers present and in most of the colonies that we have seen the total has been less than fifty individuals. This is undoubtedly due to the fact that rohweri is seldom, if ever, pleometrotic. Each of the nine colonies of rohweri which we have examined had a single queen. The nests of rohweri are established in abandoned burrows of wood-boring beetles (often those of small buprestids) which are cleared of the detritus left in them by the beetle larvae. While most of the branches selected by rohweri consist of hard, sound wood it will nest in rotten branches as well. A limb housing one of the Santa Catalina colonies was so badly decayed that the ants were extracted by crumbling the wood between the fingers. As shown elsewhere (4) texanus ordinarily rejects nest sites in rotten wood. The burrows chosen by rohweri are of a size that permits the major to occlude the terminal opening. This occlusion is like that of texanus; the opening is blocked by the head and pronotum of the major, who crouches to admit the minor. An interesting variation of this response was observed in the junior author's colony. This colony originally occupied burrows in a large, dead palo verde branch. Just inside the entrance of one of these burrows was a circular flange of detritus. The circular opening in this flange was slightly more than $2 \mathrm{~mm}$. in diameter. This opening was occluded by the cephalic disc of the major, who stood in the passage behind the flange. The workers of rohweri pack themselves tightly into the outer portion of the nest passage, as do those of texanus, but show one response under these conditions that texanus does not display. The minor worker of rohweri can reverse its position in the passage by a twisting somersault. This begins with a lowering of the head. whose forward edge is thrust under the anterior coxae. Thereafter the body is swung forward and downward and during this arc it is twisted sidewise. The end result is that when the 
minor regains its feet it is facing in the opposite direction. No major of rohweri was ever seen to behave in this way.

The foraging activities of rohweri are of interest since there is evidence that it deliberately forages on the ground. This is probably true of texanus as well but it has not yet been conclusively proved in that species. On one occasion Dr. F. G. Werner took six foraging workers of rohweri from white cholla in the Saguaro National Monument. Unless the ants were living in the cactus, which seems completely unlikely, they must have reached it over the surface of the soil. It is not clear why the foragers had visited the cholla. It was not in bloom and efforts by both writers to interest the captive colonies in cholla were unsuccessful. Workers in the aquarium colonies spent much time crawling over leaves and twigs of various plants with which they were kept supplied. When a worker fell from a leaf its righting reaction was completely different from that of texanus. When a worker of rohweri lands on its back it shows no fixed righting reaction. The body is violently contorted and the legs are flailed about until one of them anchors on something that enables the ant to pull itself over. The stereotyped righting reaction of texanus has been described elsewhere (4).

The junior author's colony was fed on diluted honey, which was supplied through a wick from a reservoir. They were also fed on the juices of phalaenid caterpillars. It was necessary to tear the caterpillars open before the workers would feed on them. Entire insects, either alive or dead, were avoided, as was pollen taken from honey bees. The colonies of the senior author were fed on pollen from the start. It was found that rohweri will accept a wide variety of pollen if it is smeared on the surface of leaves, although they seldom take it from the anthers of flowers. Of the various sorts of pollen fed to the colonies that of Quercus agrifolia was clearly the most relished. As will be shown, the colonies were also fed with aphid honey dew. As a rule they preferred this to pollen but on one occasion, while the ants were feeding on honey dew, catkins of Quercus agrifolia were placed in the aquaria. The response to these was immediate and spectacular. The foragers feeding on honey dew deserted it for the oak catkins and practically every worker turned out to take pollen from them. They gathered such quantities of pollen that they returned to the nest with masses of grains in their jaws. These masses were held against the heads of the larvae who nibbled away the pollen grains. The original experiments with honey dew were disappointing. The ants paid little attention to coccids on the leaves of Quercus chrysolepis or to the rims of liquid which surrounded them. They were definitely 
interested in Aphis fabi, a species that is abundant on Mesembryanthemum at Riverside. The ants tried to milk the aphids but the latter, who were clearly afraid of the rohweri workers, failed to coöperate. They would usually run away from the ants, which resulted in some of them being killed when the ants tried to catch them. Much better results were secured with Aphis sphaericola. This aphis produces such large quantities of honey dew that it will drip from the leaves on which the aphids are feeding. When leaves of Viburnum suspensum bearing Aphis sphaericola and coated with its honey dew were placed in the aquaria the foraging ants gorged themselves until their intersegmental gastric membranes were visible. This they did by lapping the honey dew from the surface of the leaves. The ants paid little attention to the aphids and made no attempt to milk them.

Since the colonies were well-supplied with food a number of eggs were soon present. When the major or female handles an egg it is positioned so that its long axis runs through the notch in the anterior edge of the cephalic disc. The larger eggs fit the rim of this notch closely when so positioned. Most of the eggs hatched in about 27 days. The voiding of the larval meconium was observed three times and took between 60 and 75 minutes. The movement of the black meconium, both within the larva and during its emergence is so slow that it is difficult to follow. Infrequent contractions of the posterior half of the larva probably reflect peristaltic movements of the gut within. Once outside the larva the meconium invariably attracted workers, both majors and minors, although they were never observed to assist the larva in any way. It was only after the meconium was presented that the larva was groomed. On one occasion the meconium was eaten by the attendant worker. On the other two it was carried to the dump in the feeding chamber. The period between the passing of the meconium and pupation was from six to ten days. The pupal moult was never observed. New pupae are ivory white and the first suggestions of pigmentation appear in the compound eyes. The color of the pupa darkens from yellow ochre to brown during the second and third weeks. There is a four- or five- day callow period after the adult emerges. In the senior author's colonies worker brood developed from egg to adult in about three months (egg to larva \pm 27 days; larva to pupa \pm 33 days; pupa to adult \pm 23 days). The nests were kept at room temperature and the range, for the most part, lay between $60^{\circ} \mathrm{F}$ and $70^{\circ} \mathrm{F}$. Since the temperature range to which a free colony is subjected is far wider, these figures are useful only as an indication of the relative length of the several stages. Moreover, the 
development of the larva may be drastically modified. In the junior author's colony eight males emerged during the period from July 3 to July 24, I963. These males developed from eggs which had been laid in June of 1962. These eggs developed into larvae in about a month and the larvae grew for about two months. But from September 1962 to June 1963 the larvae showed no further development. In short, these eight males over-wintered as larvae. They emerged in July and it is interesting to note that the marriage flight of rohweri occurs in that month. The senior author took a female of rohweri which had just completed her marriage flight in Baboquivari Canyon on July 28, 195 I.

\section{Literature Cited}

1. Wheeler, W. M., Proc. New Eng. Zool Club, 6, pp. 29-35 (1916)

2. Sмiтh, M. R., Proc. Ent. Soc. Wash. 49, No. 1, pp. 29-40 (1947)

3. Creighton, W. S. \& Gregg, R. E., Psyche, 61, No. 2, pp. 41-57 (1954)

4. Creighton, W. S., Psyche, 70, No. 3, pp. 133-143 (1963) 

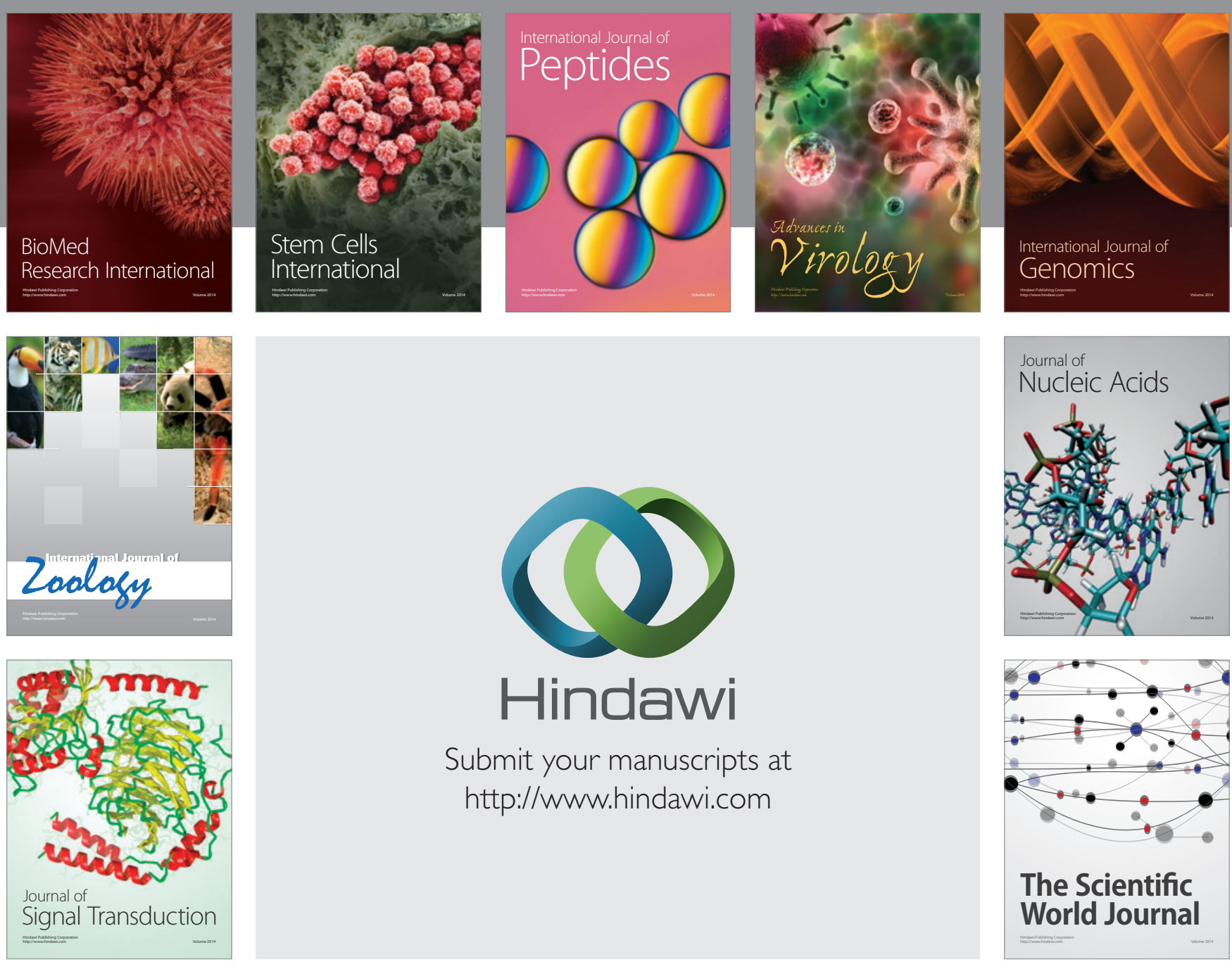

Submit your manuscripts at

http://www.hindawi.com
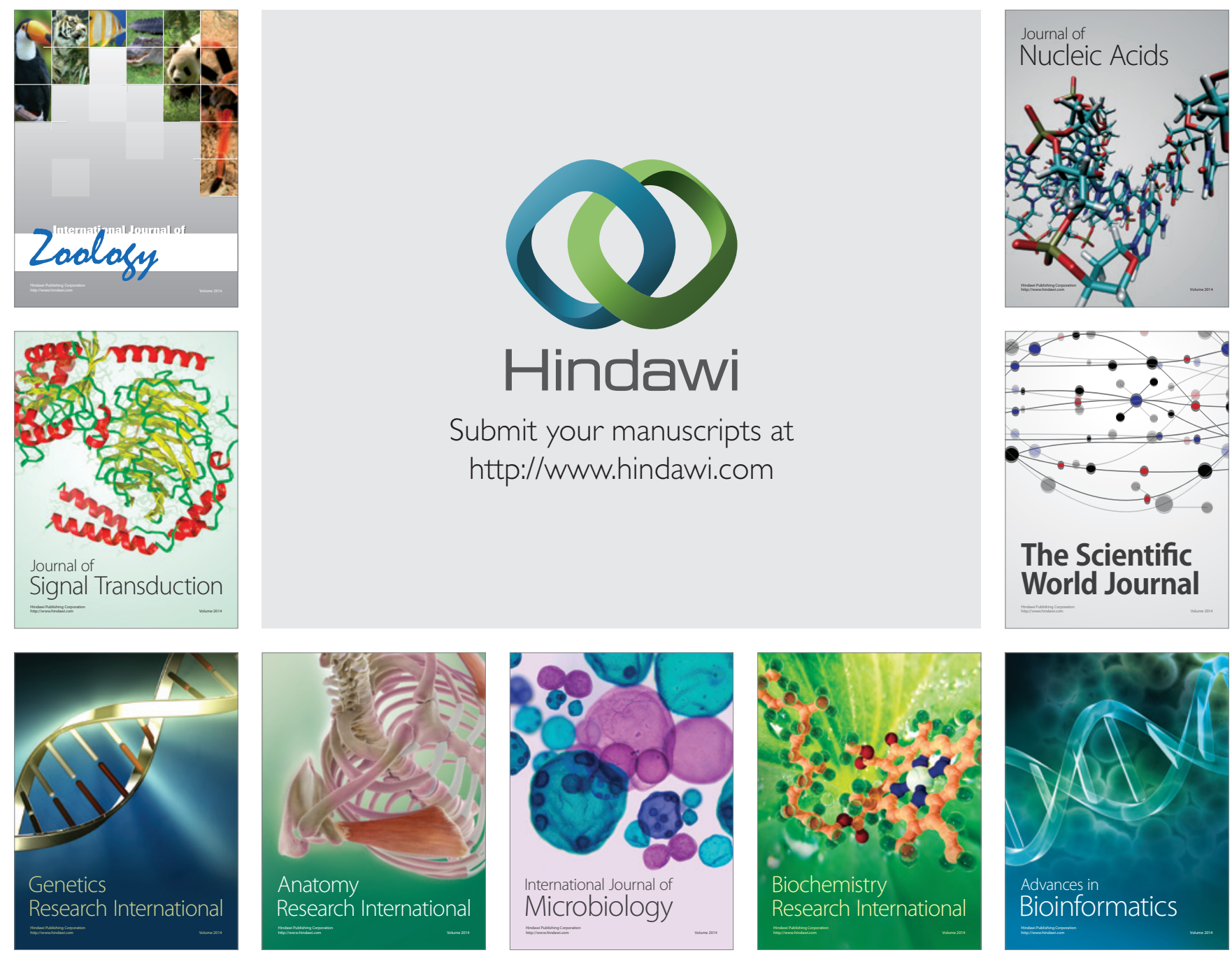

The Scientific World Journal
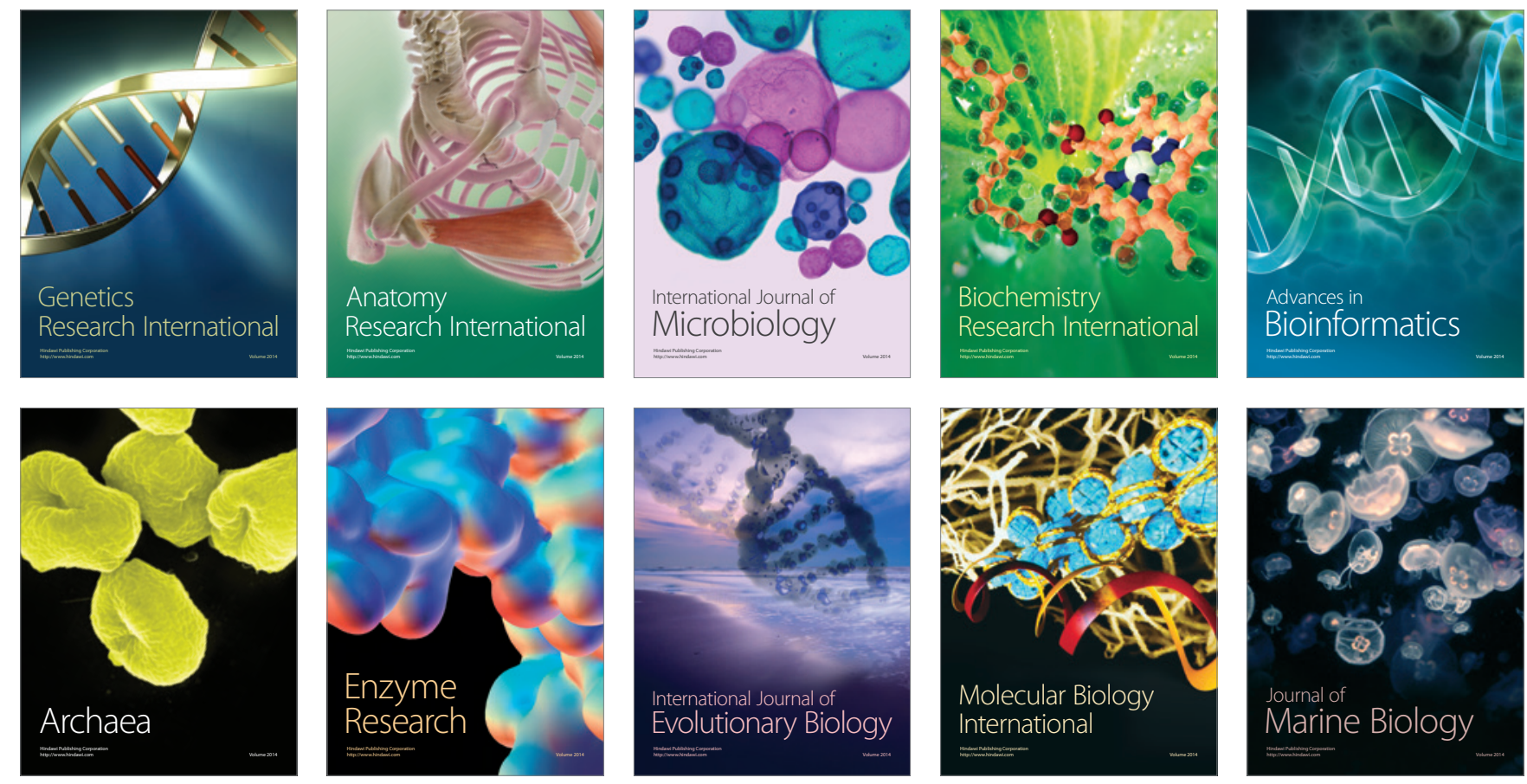